\title{
Plasma concentrations of adrenomedullin and natriuretic peptides in patients with essential hypertension
}

\author{
WEI HU ${ }^{1 *}$, PANG-HU ZHOU ${ }^{2 *}$, XIAO-BIN ZHANG ${ }^{1}$, CHANG-GENG XU $^{1}$ and WEI WANG ${ }^{1}$ \\ Departments of ${ }^{1}$ Urology and ${ }^{2}$ Orthopedics, Renmin Hospital of Wuhan University, \\ Wuhan, Hubei 430060, P.R. China
}

Received June 18, 2014; Accepted February 16, 2015

DOI: $10.3892 /$ etm.2015.2345

\begin{abstract}
This study was designed to assess any changes in the plasma concentrations of adrenomedullin (ADM) and atrial and brain natriuretic peptide (ANP and BNP, respectively), and to investigate their pathophysiological roles in patients with essential hypertension (EH). The plasma ADM, ANP and BNP concentrations were measured in 64 patients with untreated $\mathrm{EH}$ and 35 normotensive control subjects. After 4 weeks of effective antihypertensive therapy with oral drugs for the hypertensive patients, the plasma concentrations of ADM, ANP and BNP in the hypertensive patients were measured again. The plasma concentrations of ADM, ANP and BNP were significantly higher in the hypertensive patients than those in the control subjects, and the concentrations increased with the clinical stage. Furthermore, the hypertensive patients exhibited increased mean arterial pressure (MAP), blood urea nitrogen (BUN), serum creatinine (Scr) and decreased glomerular filtration rates (GFRs) compared with the control subjects. The plasma ADM concentration was not only correlated with BUN, Scr and the GFR, but was also associated with the MAP and the plasma levels of ANP and BNP. Following effective antihypertensive therapy with oral medication for 4 weeks, the plasma concentrations of ADM, ANP and BNP were significantly, but not sharply, decreased. In conclusion, ADM, along with ANP and BNP, may be involved in the mechanisms acting against a further increase in blood pressure and may be useful biomarkers for the diagnosis and treatment of hypertensive patients.
\end{abstract}

Correspondence to: Professor Xiao-Bin Zhang, Department of Urology, Renmin Hospital of Wuhan University, 238 Liberation Road, Wuhan, Hubei 430060, P.R. China

E-mail: zhangxiaobin_abc@163.com

*Contributed equally

Key words: adrenomedullin, atrial natriuretic peptide, brain natriuretic peptide, essential hypertension

\section{Introduction}

Adrenomedullin (ADM) was originally discovered in 1993 by Kitamura et al (1) following its isolation from human pheochromocytoma tissue. It has since been demonstrated that ADM can be synthesized by numerous mammalian tissues, including the adrenal medulla, endothelial and vascular smooth muscle cells, myocardium and central nervous system $(2,3)$. ADM has diverse and profound effects on cellular proliferation, contractility, migration and interaction with other neurohormonal factors, including atrial and brain natriuretic peptide (ANP and BNP, respectively) (4). The most important and known pathophysiological role of ADM is that it is a potent vasorelaxant and natriuretic peptide (5-7). ADM administered through intravenous infusion has been shown to lower blood pressure (BP) and increase the heart rate and cardiac output (8). A direct cardiostimulatory effect has also been found in the isolated perfused rat heart (9). The natriuretic peptide system consists of a group of neurohormones, including ANP and BNP (10). ANP and BNP are cardiac hormones believed to act against the elevation of blood pressure and retention of body fluid in cardiovascular diseases, such as hypertension and heart failure, through their vasorelaxant and natriuretic effects (5). ADM exerts its chief biological actions via an accumulation of intracellular cyclic adenosine monophosphate (11), while several of the actions of ANP and BNP are mediated by cyclic guanosine monophosphate (10). Since the actions of ADM are similar to those of ANP and BNP, despite differences in their intracellular signaling systems, we hypothesized that ADM functions along with ANP and BNP to act against a further elevation of blood pressure in hypertensive patients.

In the present study, the pathophysiological roles of $\mathrm{ADM}, \mathrm{ANP}$ and BNP in essential hypertension (EH) were investigated by monitoring any changes in the plasma concentrations of these peptides in untreated hypertensive patients whose disease was classified into one of three stages. These results were then compared with those of the control subjects, and comparisons were additionally made among the three disease stage groups. After 4 weeks of effective antihypertensive therapy for the hypertensive patients, the ADM, ANP and BNP levels were re-measured. These results were then compared with the pretherapy results and those of the control subjects. 


\section{Materials and methods}

Study subjects. Between August 2010 and December 2012, 64 patients with established $\mathrm{EH}$ and 35 normotensive control subjects were recruited for this study in the Renmin Hospital of Wuhan University (Wuhan, China). All subjects agreed with the aim of the study and gave their informed consent prior to their inclusion in the study. The study was approved by the Ethics Committee of Renmin Hospital of Wuhan University.

Routine laboratory studies of the patients included routine blood tests; urinalysis; prothrombin time, activated partial thromboplastin time, fibrinogen and D-Dimer concentrations; serum electrolytes, serum creatinine (Scr), blood urea nitrogen (BUN) and fasting blood glucose levels; liver function tests; plasma renin activity, aldosterone, catecholamine, cortisol and thyroid hormone levels; a chest roentgenogram; an electrocardiogram; B-scan ultrasonography of the liver, cholecyst, pancreas, spleen, bilateral kidneys and adrenal glands; and an excretory urogram or renal arteriogram. The glomerular filtration rate (GFR) was calculated by endogenous cystatin C clearance, as previously described (12). On the basis of all results and guidelines from the World Health Organization (2003) (13), subjects were placed into a diagnostic category. Normal BP was defined as a systolic pressure $<140 \mathrm{mmHg}$ and a diastolic pressure $<90 \mathrm{mmHg}$. Stage I hypertension was defined as a systolic pressure $\geq 140 \mathrm{mmHg}$ but $<160 \mathrm{mmHg}$ or a diastolic pressure $\geq 90 \mathrm{mmHg}$ but $<100 \mathrm{mmHg}$, or both. Stage II hypertension was defined as a systolic pressure $\geq 160 \mathrm{mmHg}$ but $<180 \mathrm{mmHg}$ or a diastolic pressure $\geq 100 \mathrm{mmHg}$ but $<110 \mathrm{mmHg}$, or both. Stage III hypertension was defined as a systolic pressure $\geq 180 \mathrm{mmHg}$ or a diastolic pressure $\geq 110 \mathrm{mmHg}$, or both. Secondary hypertension was excluded by clinical history, physical examination, routine laboratory tests and imaging examinations. None of the patients had clinical evidence of cardiac or hepatic failure, diabetes, pulmonary disease, angina pectoris, myocardial infarction or other diseases that could cause secondary hypertension. The hypertensive patients either had no history of antihypertensive treatment or had ceased their antihypertensive treatment $\geq 4$ weeks previously. The normotensive controls were age- and gender-matched healthy subjects who had been hospitalized for a healthy checkup.

Following the initial evaluation, the plasma concentrations of ADM, ANP and BNP were determined. A total of 64 patients with $\mathrm{EH}$ then commenced antihypertensive therapy with one or more of the following drugs: Nifedipine, metoprolol or benazepril. After 4 weeks of effective antihypertensive therapy, the $\mathrm{BP}$ of the hypertensive patients was normalized. The plasma levels of the three peptides were then re-measured.

Arterial BP was measured by a mercury sphygmomanometer once the patients had rested in a seated position for $\geq 30 \mathrm{~min}$ in a quiet and warm room without smoking or drinking coffee. The mean of three BP measurements at 5-min intervals was used to classify the subjects.

Preparations of human ADM (hADM), ANP and BNP. Blood samples were drawn from an antecubital vein early in the morning following an overnight fast and were transferred to ice-chilled tubes containing aprotinin $(500 \mathrm{KIU} / \mathrm{ml})$ and EDTA $(1 \mathrm{~g} / \mathrm{l})$. Plasma was separated by centrifugation at
$2,000 \mathrm{xg}$ for $10 \mathrm{~min}$ at $4^{\circ} \mathrm{C}$ and immediately frozen and stored at $-70^{\circ} \mathrm{C}$ until radioimmunoassay (RIA).

Assay procedure. The plasma ADM concentrations were measured with a specific RIA following the extraction of plasma, as described previously (14). Briefly, $2 \mathrm{ml}$ plasma was loaded onto a Sep-Pak C18 cartridge (Waters Corp., Milford, MA, USA) equilibrated with $5 \mathrm{ml}$ saline. Following the washing of the cartridge with $5 \mathrm{ml}$ saline and $10 \%$ acetonitrile in $0.1 \%$ trifluoroacetic acid (TFA), the absorbed peptides were eluted with $4 \mathrm{ml} 50 \%$ acetonitrile in $0.1 \%$ TFA, lyophilized, and then stored at $-70^{\circ} \mathrm{C}$ until RIA. The plasma extract was dissolved in $250 \mu$ l RIA buffer (Phoenix Pharmaceuticals, Inc., Mountain View, CA, USA) and $50 \mathrm{mmol} / 1$ sodium phosphate buffer ( $\mathrm{pH}$ 7.4) containing $0.5 \%$ bovine serum albumin, $0.5 \%$ Triton X-100, $80 \mathrm{mmol} / 1$ sodium chloride, $25 \mathrm{mmol} / \mathrm{l}$ EDTA, $0.05 \%$ sodium azide and $500 \mathrm{KIU} / \mathrm{ml}$ aprotinin. A total of $100 \mu 1$ dissolved plasma extract was used for an hADM-specific RIA, as reported previously (14). The rabbit polyclonal anti-hADM antibody (1:20,000; cat. no. RK-010-01; Phoenix Pharmaceuticals, Inc.) used in this RIA did not show any cross-reactivity with hADM-(13-52), rat ADM-(1-50), human calcitonin gene-related peptide (CGRP), endothelin-1, $\alpha$-human ANP-(1-28), BNP-32 or C-type natriuretic peptide-22. The interassay coefficient of variation was $8 \%$, and the intra-assay coefficient of variation was $6 \%$. The concentration of ADM was expressed in $\mathrm{ng} / \mathrm{l}$.

The plasma ANP concentration was determined by a similar specific immunoradiometric assay for human ANP (ShionoRIA ANP kit; Shionogi \& Co., Ltd., Osaka, Japan). The plasma BNP concentration was measured by a similar method developed by the same company (ShionoRIA BNP kit; Shionogi \& Co., Ltd.). The accuracies and the detailed methods of these assays have been described previously (15).

Statistical analysis. All continuous data are expressed as the mean \pm standard deviation. Statistical analysis was performed through linear regression analysis, which was further confirmed by Kendall's method or an analysis of variance test for multiple comparisons, which was further examined using the Student-Newman-Keuls's method. Comparisons between two variables were conducted using an unpaired t-test, and comparisons between the paired values were analyzed with a paired t-test. Categorical variables were assessed using the $\chi^{2}$ or Fisher's exact test. Non-normally distributed data were analyzed through the Mann-Whitney U test. $\mathrm{P}<0.05$ was considered to indicate a statistically significant difference.

\section{Results}

Baseline characteristics. The clinical profiles of the control subjects and hypertensive patients in each stage are summarized in Table I. No significant differences were found in the age and gender distribution among the four groups. The mean arterial pressure (MAP), BUN and Scr levels of the hypertensive patients were significantly higher than those of the control subjects $(\mathrm{P}<0.05)$; these increases additionally correlated with the severity of the hypertension stage $(\mathrm{P}<0.05)$. The GFRs of the hypertensive patients exhibited the opposite changes $(\mathrm{P}<0.05)$. 
Table I. Characteristics of the study subjects.

\begin{tabular}{|c|c|c|c|c|}
\hline & Control, $n=35$ & Stage I EH, $\mathrm{n}=20$ & Stage II EH, n=25 & Stage III EH, $n=19$ \\
\hline Age (years) & $43 \pm 4$ & $41 \pm 6$ & $44 \pm 5$ & $45 \pm 7$ \\
\hline Male:female ratio (n:n) & $16: 19$ & $9: 11$ & $11: 14$ & $8: 11$ \\
\hline $\mathrm{MAP}(\mathrm{mmHg})$ & $90 \pm 8$ & $112 \pm 5^{\mathrm{a}}$ & $124 \pm 8^{\mathrm{a}, \mathrm{b}}$ & $138 \pm 10^{\mathrm{a}, \mathrm{b}, \mathrm{c}}$ \\
\hline BUN (mg/dl) & $17 \pm 3$ & $19 \pm 2^{\mathrm{a}}$ & $22 \pm 3^{\mathrm{a}, \mathrm{b}}$ & $26 \pm 6^{a, b, c}$ \\
\hline $\operatorname{Scr}(\mathrm{mg} / \mathrm{dl})$ & $1.0 \pm 0.2$ & $1.2 \pm 0.3^{\mathrm{a}}$ & $1.5 \pm 0.4^{\mathrm{a}, \mathrm{b}}$ & $1.8 \pm 0.5^{\mathrm{a}, \mathrm{b}, \mathrm{c}}$ \\
\hline GFR (ml/min) & $95 \pm 9$ & $87 \pm 9^{a}$ & $79 \pm 10^{\mathrm{a}, \mathrm{b}}$ & $72 \pm 11^{\mathrm{a}, \mathrm{b}, \mathrm{c}}$ \\
\hline
\end{tabular}

${ }^{\mathrm{a}} \mathrm{P}<0.05$ compared with control subjects; ${ }^{\mathrm{b}} \mathrm{P}<0.05$ compared with stage I EH patients; ${ }^{\mathrm{c}} \mathrm{P}<0.05$ compared with stage II EH patients. MAP, mean arterial pressure; BUN, blood urea nitrogen; Scr, serum creatinine; GFR, glomerular filtration rate; EH, essential hypertension.

A

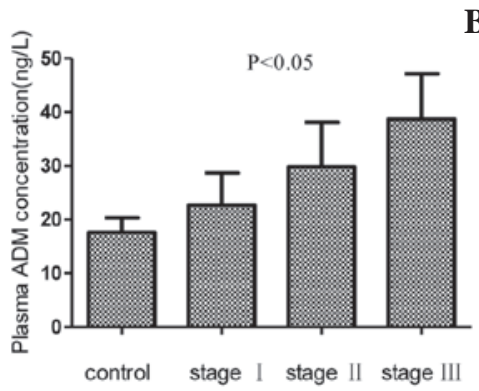

B

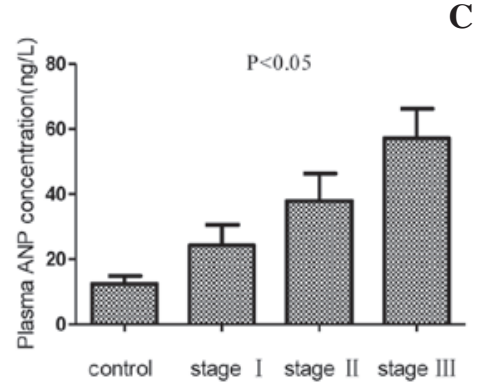

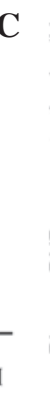

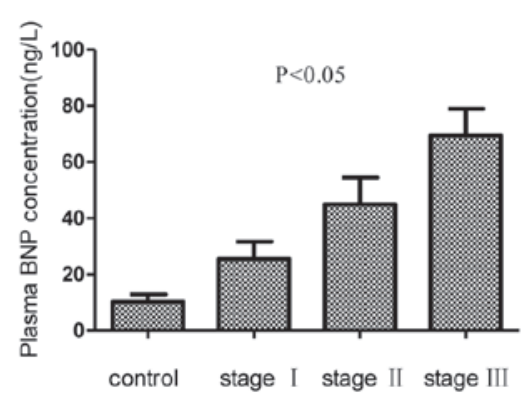

Figure 1. Plasma concentrations of (A) ADM, (B) ANP and (C) BNP in the control and three hypertension groups. ADM, adrenomedullin; ANP, atrial natriuretic peptide; BNP, brain natriuretic peptide.

A

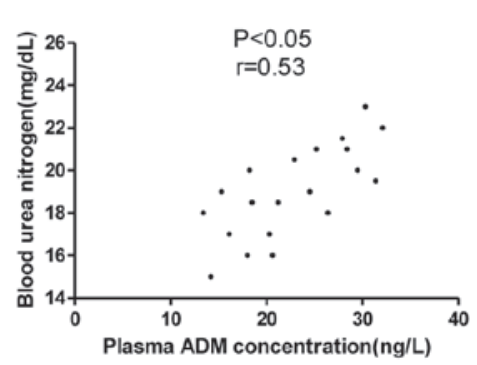

B

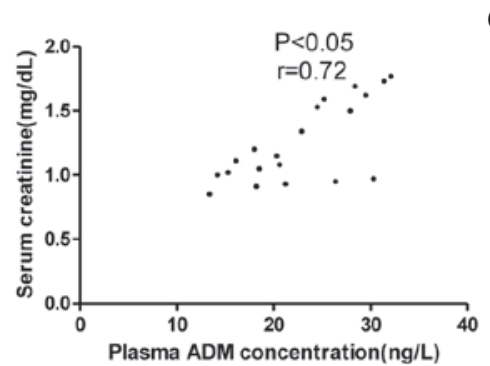

C

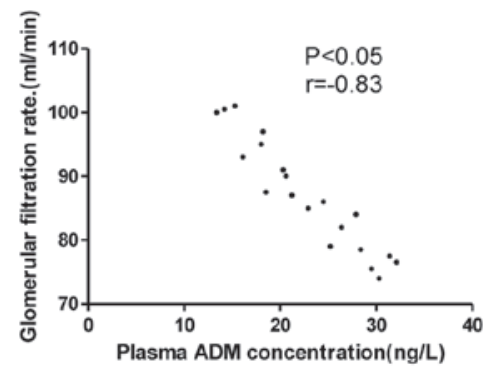

Figure 2. Association between plasma ADM concentration and (A) blood urea nitrogen, (B) serum creatinine and (C) glomerular filtration rate in the stage I hypertension group. ADM, adrenomedullin.

Pretherapy peptide levels. Fig. 1 shows the plasma concentrations of ADM, ANP and BNP in the control and three hypertension groups. The mean concentrations of ADM, ANP and BNP in the hypertension groups were significantly higher than those in the control group $(\mathrm{P}<0.05)$; significant increases were additionally found with increases in the hypertension grade $(\mathrm{P}<0.05)$.

The associations between the plasma ADM concentration and the BUN level, Scr level and GFR in the stage I, II and III hypertension groups are summarized in Figs. 2-4. The plasma ADM concentration was correlated with BUN and a stronger correlation with Scr was found. The strongest correlation was observed between the plasma ADM concentration and the GFR but this correlation was negative.

The associations between the plasma ADM concentration and the MAP, ANP and BNP levels in the stage I, II and III hypertension groups are summarized in Figs. 5-7. The ADM concentration was not only correlated with MAP but also with the plasma concentrations of ANP and BNP.

The plasma concentrations of ADM, ANP and BNP in the stage I, II and III hypertension groups with or without renal dysfunction are summarized in Tables II-IV. The patients with increased Scr $(\geq 1.5 \mathrm{mg} / \mathrm{dl})$ or decreased GFR $(\leq 80 \mathrm{ml} / \mathrm{min})$ had markedly higher plasma concentrations of ADM, ANP and BNP than those of the patients with normal Scr and GFR. The plasma ADM, ANP and BNP levels of the patients with or without renal dysfunction were also higher than those of control subjects.

Post-therapy results. Table V shows the clinical parameters of the three groups of hypertensive patients initially and 4 weeks after effective antihypertensive therapy. Following treatment, the MAP of the patients was normal, while the BUN and Scr levels were decreased compared with the pretherapy values 
A

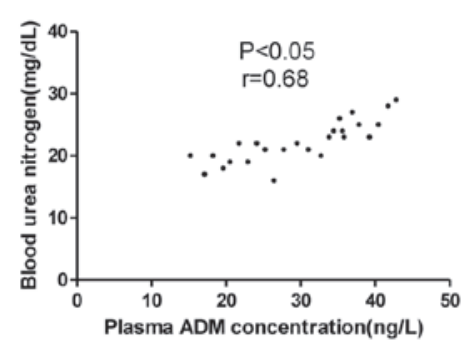

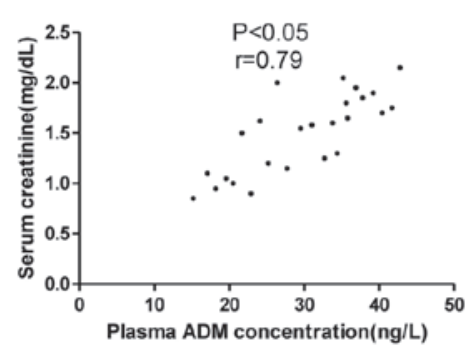
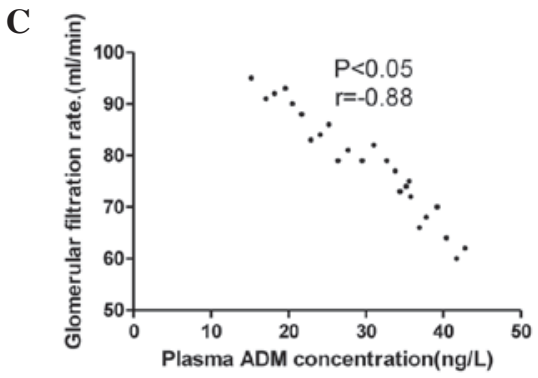

Figure 3. Association between plasma ADM concentration and (A) blood urea nitrogen, (B) serum creatinine and (C) glomerular filtration rate in the stage II hypertension group. ADM, adrenomedullin.

A

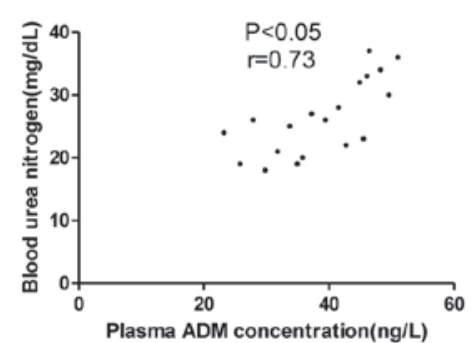

B

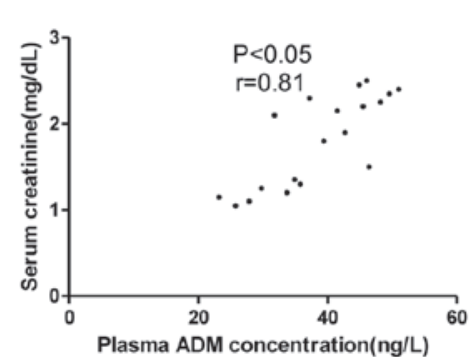

C

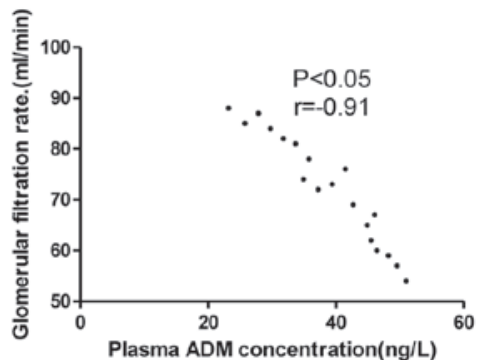

Figure 4. Association between plasma ADM concentration and (A) blood urea nitrogen, (B) serum creatinine and (C) glomerular filtration rate in the stage III hypertension group. ADM, adrenomedullin.

A

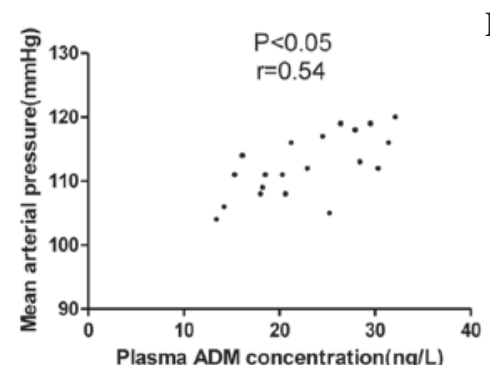

B

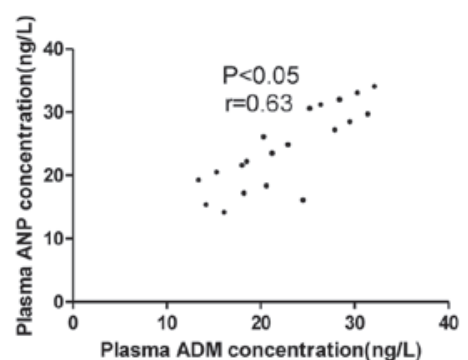

C

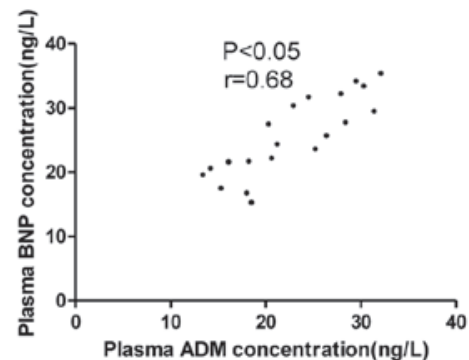

Figure 5. Association between plasma ADM concentration and (A) mean arterial pressure, (B) ANP and (C) BNP in the stage I hypertension group. ADM, adrenomedullin; ANP, atrial natriuretic peptide; BNP, brain natriuretic peptide.

A

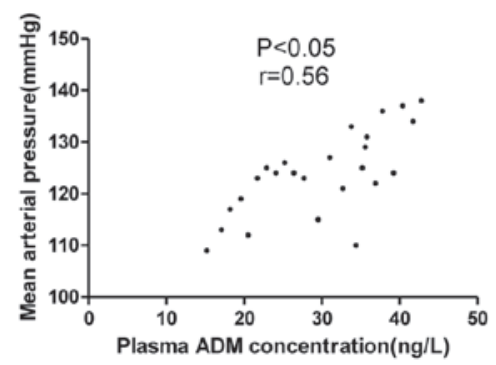

B

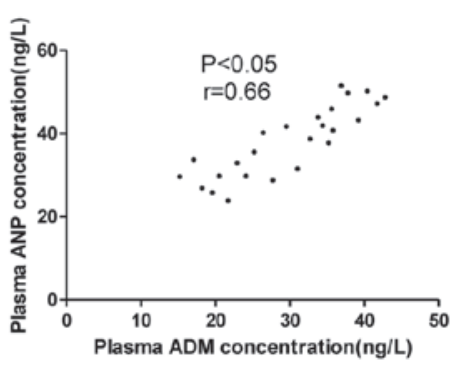

C

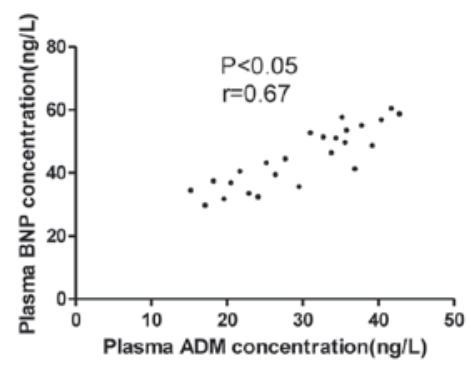

Figure 6. Association between plasma ADM concentration and (A) mean arterial pressure, (B) ANP and (C) BNP in the stage II hypertension group. ADM, adrenomedullin; ANP, atrial natriuretic peptide; BNP, brain natriuretic peptide.

$(\mathrm{P}<0.05)$. By contrast, the GFR was increased compared with the pretherapy values $(\mathrm{P}<0.05)$.

The plasma ADM, ANP and BNP concentrations in the stage I, II and III hypertension groups initially and 4 weeks after effective antihypertensive therapy are summarized in Figs. 8-10. The plasma concentrations of ADM, ANP and BNP fell significantly following antihypertensive treatment $(\mathrm{P}<0.05)$.

\section{Discussion}

As a 52-amino acid vasodilatory peptide, ADM has a ring structure formed by a disulfide bond and an amidated carboxyl terminus and shows homology with CGRP and amylin, which are other members of this family of peptides (16). It has been demonstrated that this peptide is present not only in a variety 
Table II. Plasma concentrations of ADM, ANP and BNP in stage I hypertensive patients with or without renal dysfunction.

\begin{tabular}{lrlll}
\hline Characteristics & $\mathrm{n}$ & ADM $(\mathrm{ng} / \mathrm{l})$ & ANP $(\mathrm{ng} / \mathrm{l})$ & BNP (ng/l) \\
\hline Scr $\geq 1.5 \mathrm{mg} / \mathrm{dl}$ & 7 & $29.4 \pm 2.0^{\mathrm{a}, \mathrm{b}}$ & $31.3 \pm 1.9^{\mathrm{a}, \mathrm{b}}$ & $32.4 \pm 2.1^{\mathrm{a}, \mathrm{b}}$ \\
$\mathrm{Scr}<1.5 \mathrm{mg} / \mathrm{dl}$ & 13 & $19.1 \pm 3.8^{\mathrm{b}}$ & $20.5 \pm 4.2^{\mathrm{b}}$ & $21.9 \pm 3.9^{\mathrm{b}}$ \\
GFR $\leq 80 \mathrm{ml} / \mathrm{min}$ & 6 & $29.9 \pm 1.7^{\mathrm{b}, \mathrm{c}}$ & $31.8 \pm 1.6^{\mathrm{b}, \mathrm{c}}$ & $32.9 \pm 1.8^{\mathrm{b}, \mathrm{c}}$ \\
GFR $>80 \mathrm{ml} / \mathrm{min}$ & 14 & $19.6 \pm 4.0^{\mathrm{b}}$ & $21.1 \pm 4.6^{\mathrm{b}}$ & $22.4 \pm 4.3^{\mathrm{b}}$ \\
Control subjects & 35 & $17.6 \pm 2.7$ & $12.5 \pm 2.4$ & $10.3 \pm 2.6$ \\
\hline
\end{tabular}

${ }^{\mathrm{a}} \mathrm{P}<0.05$ compared with patients with normal Scr levels; ${ }^{\mathrm{b}} \mathrm{P}<0.05$ compared with control subjects; ${ }^{\mathrm{c}} \mathrm{P}<0.05$ compared with patients with normal GFR. Scr, serum creatinine; GFR, glomerular filtration rate; ADM, adrenomedullin; ANP, atrial natriuretic peptide; BNP, brain natriuretic peptide.

Table III. Plasma concentrations of ADM, ANP and BNP in stage II hypertensive patients with or without renal dysfunction.

\begin{tabular}{lllll}
\hline Characteristics & $\mathrm{n}$ & ADM (ng/l) & ANP (ng/l) & BNP (ng/l) \\
\hline Scr $\geq 1.5 \mathrm{mg} / \mathrm{dl}$ & 15 & $35.6 \pm 4.4^{\mathrm{a}, \mathrm{b}}$ & $43.8 \pm 4.9^{\mathrm{a}, \mathrm{b}}$ & $51.4 \pm 5.9^{\mathrm{a}, \mathrm{b}}$ \\
$\mathrm{Scr}<1.5 \mathrm{mg} / \mathrm{dl}$ & 10 & $21.1 \pm 3.6^{\mathrm{b}}$ & $29.2 \pm 3.1^{\mathrm{b}}$ & $35.2 \pm 3.5^{\mathrm{b}}$ \\
$\mathrm{GFR} \leq 80 \mathrm{ml} / \mathrm{min}$ & 14 & $36.2 \pm 3.9^{\mathrm{b}, \mathrm{c}}$ & $44.4 \pm 4.5^{\mathrm{b}, \mathrm{c}}$ & $52.2 \pm 5.3^{\mathrm{b}, \mathrm{c}}$ \\
GFR $>80 \mathrm{ml} / \mathrm{min}$ & 11 & $21.7 \pm 4.0^{\mathrm{b}}$ & $29.8 \pm 3.5^{\mathrm{b}}$ & $35.8 \pm 3.8^{\mathrm{b}}$ \\
Control subjects & 35 & $17.6 \pm 2.7$ & $12.5 \pm 2.4$ & $10.3 \pm 2.6$ \\
\hline
\end{tabular}

${ }^{\mathrm{a}} \mathrm{P}<0.05$ compared with patients with normal Scr levels; ${ }^{\mathrm{b}} \mathrm{P}<0.05$ compared with control subjects; ${ }^{\mathrm{c}} \mathrm{P}<0.05$ compared with patients with normal GFR. Scr, serum creatinine; GFR, glomerular filtration rate; ADM, adrenomedullin; ANP, atrial natriuretic peptide; BNP, brain natriuretic peptide.

Table IV. Plasma concentrations of ADM, ANP and BNP in stage III hypertensive patients with or without renal dysfunction.

\begin{tabular}{lrlll}
\hline Characteristics & $\mathrm{n}$ & ADM (ng/l) & ANP (ng/l) & BNP (ng/l) \\
\hline Scr $\geq 1.5 \mathrm{mg} / \mathrm{dl}$ & 12 & $44.0 \pm 4.8^{\mathrm{a}, \mathrm{b}}$ & $62.9 \pm 5.9^{\mathrm{a}, \mathrm{b}}$ & $75.3 \pm 6.1^{\mathrm{a}, \mathrm{b}}$ \\
Scr $<1.5 \mathrm{mg} / \mathrm{dl}$ & 7 & $29.6 \pm 4.2^{\mathrm{b}}$ & $47.7 \pm 3.4^{\mathrm{b}}$ & $59.5 \pm 4.3^{\mathrm{b}}$ \\
GFR $\leq 80 \mathrm{ml} / \mathrm{min}$ & 13 & $43.3 \pm 5.2^{\mathrm{b}, \mathrm{c}}$ & $62.1 \pm 6.4^{\mathrm{b}, \mathrm{c}}$ & $74.5 \pm 6.5^{\mathrm{b}, \mathrm{c}}$ \\
GFR $>80 \mathrm{ml} / \mathrm{min}$ & 6 & $28.7 \pm 3.9^{\mathrm{b}}$ & $46.9 \pm 2.9^{\mathrm{b}}$ & $58.5 \pm 3.8^{\mathrm{b}}$ \\
Control subjects & 35 & $17.6 \pm 2.7$ & $12.5 \pm 2.4$ & $10.3 \pm 2.6$ \\
\hline
\end{tabular}

${ }^{\mathrm{a}} \mathrm{P}<0.05$ compared with patients with normal Scr levels; ${ }^{\mathrm{b}} \mathrm{P}<0.05$ compared with control subjects; ${ }^{\mathrm{c}} \mathrm{P}<0.05$ compared with patients with normal GFR. Scr, serum creatinine; GFR, glomerular filtration rate; ADM, adrenomedullin; ANP, atrial natriuretic peptide; BNP, brain natriuretic peptide.
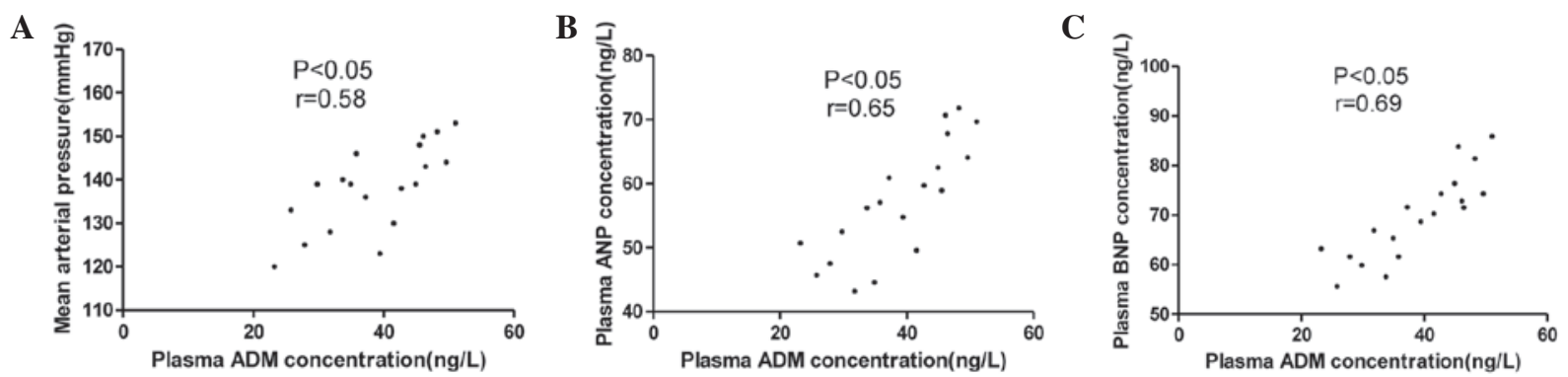

Figure 7. Association between plasma ADM concentration and (A) mean arterial pressure, (B) ANP and (C) BNP in the stage III hypertension group. ADM, adrenomedullin; ANP, atrial natriuretic peptide; BNP, brain natriuretic peptide.

of organs and cells, but also in human plasma (1). Factors of both the physical, such as shear and ventricular wall stress and hypoxia, and humoral, such as cytokines and endocrine and paracrine hormones, variety are known to affect the synthesis of ADM (16). Compared with control subjects, it has been found that the plasma levels of ADM are increased in patients 
Table V. Hemodynamic parameters of the hypertensive subjects.

\begin{tabular}{|c|c|c|c|c|c|c|}
\hline \multirow[b]{2}{*}{ Parameters } & \multicolumn{2}{|c|}{ Stage I EH, $\mathrm{n}=20$} & \multicolumn{2}{|c|}{ Stage II EH, n=25 } & \multicolumn{2}{|c|}{ Stage III EH, n=19 } \\
\hline & At diagnosis & After drugs & At diagnosis & After drugs & At diagnosis & After drugs \\
\hline MAP (mmHg) & $112 \pm 5$ & $92 \pm 3^{\mathrm{a}}$ & $124 \pm 8$ & $94 \pm 4^{\mathrm{a}}$ & $138 \pm 10$ & $95 \pm 5^{\mathrm{a}}$ \\
\hline BUN (mg/dl) & $19 \pm 2$ & $17 \pm 2^{\mathrm{a}}$ & $22 \pm 3$ & $19 \pm 2^{\mathrm{a}}$ & $26 \pm 6$ & $22 \pm 3^{\mathrm{a}}$ \\
\hline $\operatorname{Scr}(\mathrm{mg} / \mathrm{dl})$ & $1.2 \pm 0.3$ & $1.0 \pm 0.2^{\mathrm{a}}$ & $1.5 \pm 0.4$ & $1.2 \pm 0.2^{\mathrm{a}}$ & $1.8 \pm 0.5$ & $1.4 \pm 0.3^{\mathrm{a}}$ \\
\hline $\operatorname{GFR}(\mathrm{ml} / \mathrm{min})$ & $87 \pm 9$ & $93 \pm 7^{\mathrm{a}}$ & $79 \pm 10$ & $88 \pm 9^{\mathrm{a}}$ & $72 \pm 11$ & $84 \pm 9^{a}$ \\
\hline
\end{tabular}

${ }^{\mathrm{a}} \mathrm{P}<0.05$ compared with subjects at diagnosis. MAP, mean arterial pressure; BUN, blood urea nitrogen; Scr, serum creatinine; GFR, glomerular filtration rate; $\mathrm{EH}$, essential hypertension.

A

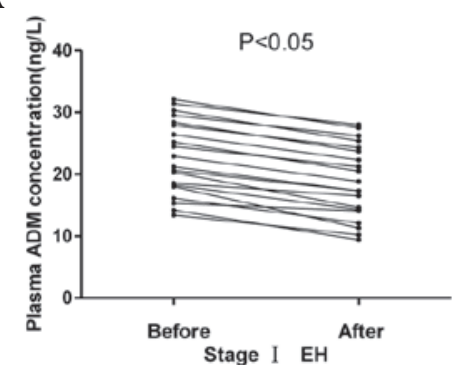

B

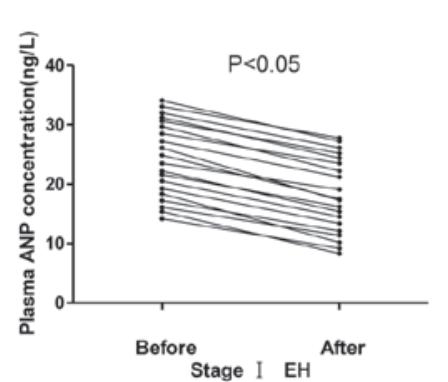

C

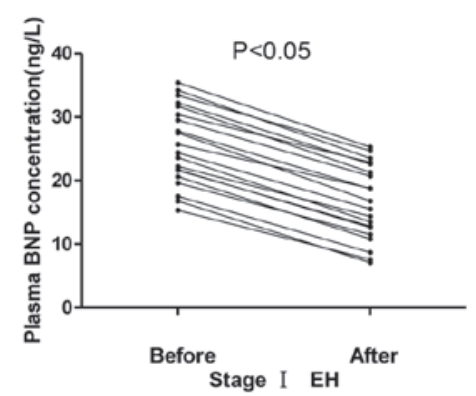

Figure 8. Plasma (A) ADM, (B) ANP and (C) BNP concentrations before and after treatment in the stage I hypertension group. ADM, adrenomedullin; ANP, atrial natriuretic peptide; BNP, brain natriuretic peptide; EH, essential hypertension.

A

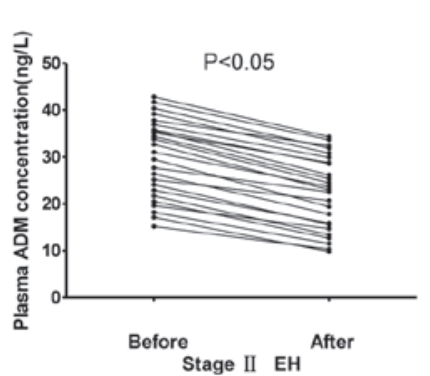

B

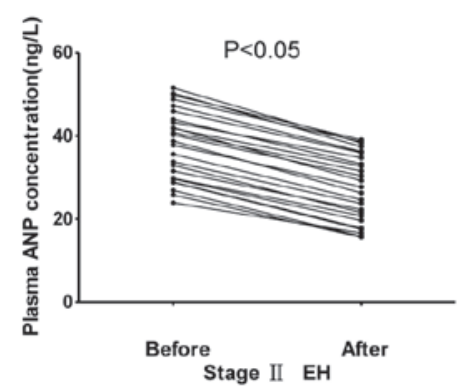

C

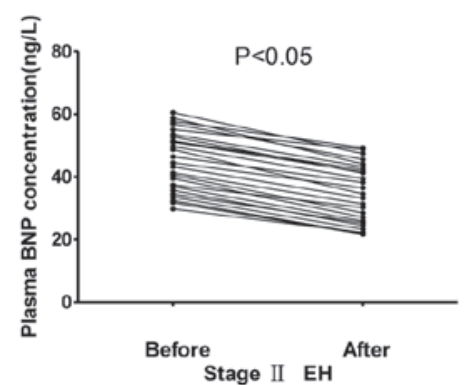

Figure 9. Plasma (A) ADM, (B) ANP and (C) BNP concentrations before and after treatment in the stage II hypertension group. ADM, adrenomedullin; ANP, atrial natriuretic peptide; BNP, brain natriuretic peptide; EH, essential hypertension.

A

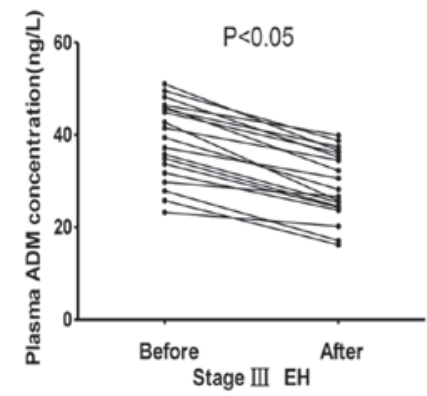

B

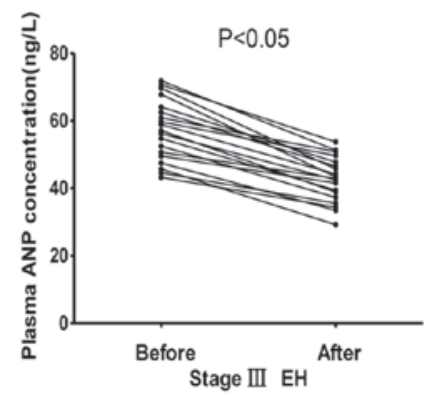

C

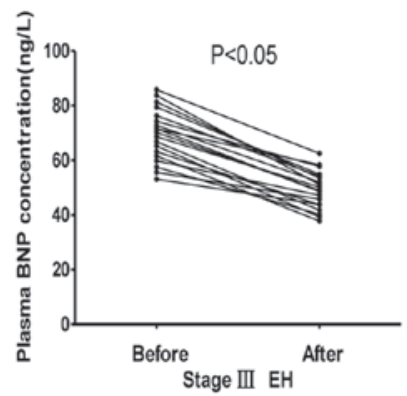

Figure 10. Plasma (A) ADM, (B) ANP and (C) BNP concentrations before and after treatment in the stage III hypertension group. ADM, adrenomedullin; ANP, atrial natriuretic peptide; BNP, brain natriuretic peptide; EH, essential hypertension.

with hypertension, heart failure or arteriosclerosis $(17,18)$. Results from genetic manipulation and prolonged low-dose infusion experiments have indicated that ADM acts to suppress increases in blood pressure and limit the progression 
of hypertensive organ damage through its protective effects on cardiovascular tissues $(19,20)$. ANP and BNP exert similar cardiovascular effects to ADM, including natriuresis, diuresis and vasodilatation (21).

In the present study, consistent with a previous investigation by Kohno et al (22), the MAP, BUN and Scr levels were elevated in patients with $\mathrm{EH}$ and increased with the severity of the hypertension stage; by contrast, GFR exhibited the opposite changes. The elevated MAP can be simply explained, and the changes in the BUN and Scr levels and GFR may have resulted from the renal damage caused by the hypertension, with more severe changes occurring with a higher disease stage.

It has been demonstrated that ADM has a broad spectrum of biological actions, including potent vasodilatation, natriuresis, inhibition of renin and aldosterone secretion, and inhibition of vascular smooth muscle cell proliferation and migration (23). ANP and BNP, which are predominantly secreted from the atrium and ventricle in the heart, respectively, function as hormones acting against a further elevation in BP in hypertensive patients through their natriuretic and vasodilatory effects (24).

In the present study, the plasma concentrations of ADM, ANP and BNP increased with increasing disease severity in the patients with $\mathrm{EH}$, a finding consistent with that in a previous study by Kato et al (5). It appears, therefore, that high BP is an important factor involved in the observed elevation of the three peptides in the plasma; as previously mentioned, the renal damage was more serious with higher BP. The metabolism of ADM primarily occurs in the kidney, and ADM concentration was positively correlated with the BUN and Scr levels but negatively correlated with the GFR in three groups of hypertensive patients. It is possible, therefore, that the reduced renal clearance of peptides accounted for the elevations in the levels of these bioactive peptides in patients with EH. This was further confirmed by the fact that the plasma ADM, ANP and BNP concentrations of the hypertensive patients with renal dysfunction were significantly higher than the values of the control subjects and hypertensive subjects without renal dysfunction. Furthermore, the plasma ADM level was strongly correlated with the level of ANP and BNP. It can be inferred that ADM, along with ANP and BNP, may be involved in the mechanisms counteracting a further elevation in BP due to their similar physiological roles, and that this is a protective and compensatory mechanism in the cardiovascular system. This theory was supported by the association between ADM and MAP and higher plasma ADM, ANP and BNP levels in hypertensive patients without renal dysfunction compared with control subjects. In addition, it was noted that the plasma levels of ADM, ANP and BNP were significantly, but not sharply, decreased due to the improvement in MAP and renal function following antihypertensive treatment for 4 weeks; therefore, the delivery of ADM, ANP and BNP to the tissue either through exogenous administration or the augmentation of endogenous production should be considered as a potential therapeutic strategy for a number of disorders, particularly hypertension. It was reported by Kato et al (5), however, that although the plasma ADM level was significantly decreased following urgent antihypertensive treatment in malignant hypertensive patients, the values of ANP and BNP were not. In addition, Kohno et al (22) found that the plasma ADM and Scr levels were not significantly changed following antihypertensive treatment for 4 weeks. The most likely explanations may be that i) a number of elderly hypertensive patients, whose renal function may not have easily improved if impaired by hypertension, were included in the study by Kohno et al (22); ii) the duration of the hypertension was different; and iii) the statistical analysis was different.

Numerous studies have found increased plasma ADM, ANP and BNP levels in patients with EH or secondary hypertension $(21,25)$; however, there are few reports on the concentrations of these values in cases of hypertension that has been classified into stages. The present study indicated that the correlation between the ADM and BUN levels became stronger as the severity of the hypertension increased. Similar correlations between ADM and Scr levels and between the ADM level and GFR were observed. It can be inferred that the ADM level is associated with renal function and that the lower renal clearance of ADM results from the increasingly serious renal damage caused by hypertension.

With regard to the physiological roles of ADM, ANP and BNP, the results of the present study suggest that ADM may be involved, along with ANP and BNP, in mechanisms counteracting a further elevation in BP and may be useful biomarkers for the diagnosis and treatment of patients with EH. Furthermore, the plasma concentrations of ADM, ANP and BNP are strongly associated with renal function. Further studies are necessary to clarify the specific physiological significance of ADM, ANP and BNP in EH and to elucidate the exact pharmacokinetics of these peptides in hypertensive patients with renal functional damage.

\section{Acknowledgements}

This study was supported by grants from the National Science Fund Project of China (no. 81200501) and the Doctor Research Fund Project of Wuhan University of China (no. 2012302020203). The authors would like to thank the Department of Urology and Cardiology in Renmin Hospital of Wuhan University.

\section{References}

1. Kitamura K, Kangawa K, Kawamoto M, et al: Adrenomedullin: A novel hypotensive peptide isolated from human pheochromocytoma. Biochem Biophys Res Commun 192: 553-560, 1993.

2. Hay DL, Walker CS and Poyner DR: Adrenomedullin and calcitonin gene-related peptide receptors in endocrine-related cancers: Opportunities and challenges. Endocr Relat Cancer 18: C1-C14, 2010.

3. Beltowski J and Jamroz A: Adrenomedullin - what do we know 10 years since its discovery? Pol J Pharmacol 56: 5-27, 2004.

4. Eto T: A review of the biological properties and clinical implications of adrenomedullin and proadrenomedullin $\mathrm{N}$-terminal 20 peptide (PAMP), hypotensive and vasodilating peptides. Peptides 22: 1693-1711, 2001.

5. Kato J, Kitamura K, Matsui E, et al: Plasma adrenomedullin and natriuretic peptides in patients with essential or malignant hypertension. Hypertens Res 22: 61-65, 1999.

6. Ishimitsu T, Ono H, Minami J and Matsuoka H: Pathophysiologic and therapeutic implications of adrenomedullin in cardiovascular disorders. Pharmacol Ther 111: 909-927, 2006.

7. Li Y, Jiang C, Wang X, Zhang Y, Shibahara S and Takahashi K: Adrenomedullin is a novel adipokine: Adrenomedullin in adipocytes and adipose tissues. Peptides 28: 1129-1143, 2007. 
8. Lainchbury JG, Troughton RW, Lewis LK, Yandle TG, Richards AM and Nicholls MG: Hemodynamic, hormonal and renal effects of short-term adrenomedullin infusion in healthy volunteers. J Clin Endocrinol Metab 85: 1016-1020, 2000.

9. Szokodi I, Kinnunen P and Ruskoaho H: Inotropic effect of adrenomedullin in the isolated perfused rat heart. Acta Physiol Scand 156: 151-152, 1996.

10. Federico C: Natriuretic Peptide system and cardiovascular disease. Heart Views 11: 10-15, 2010.

11. Kitamura K and Eto T: Adrenomedullin - physiological regulator of the cardiovascular system or biochemical curiosity? Curr Opin Nephrol Hypertens 6: 80-87, 1997.

12. Herget-Rosenthal S, Bökenkamp A and Hofmann W: How to estimate GFR-serum creatinine, serum cystatin $\mathrm{C}$ or equations? Clin Biochem 40: 153-161, 2007.

13. Whitworth JA; World Health Organiztion, International Society of Hypertension Writing Group: 2003 World Health Organization (WHO)/International Society of Hypertension (ISH) statement on management of hypertension. J Hypertens 21: 1983-1992, 2003.

14. Kitamura K, Ichiki Y, Tanaka M, et al: Immunoreactive adrenomedullin in human plasma. FEBS Lett 341: 288-290, 1994.

15. Wang Y, Zhou Y, Meng L, Lu X, Ou N and Li X: Inflammatory mediators in Chinese patients with congestive heart failure. J Clin Pharmacol 49: 591-599, 2009.

16. Cheung BM and Tang F: Adrenomedullin: Exciting new horizons. Recent Pat Endocr Metab Immune Drug Discov 6: 4-17, 2012.

17. Suzuki Y, Horio T, Hayashi T, et al: Plasma adrenomedullin concentration is increased in patients with peripheral arterial occlusive disease associated with vascular inflammation. Regul Pept 118: 99-104, 2004.
18. Kato J, Kitamura K and Eto T: Plasma adrenomedullin level and development of hypertension. J Hum Hypertens 20: 566-570, 2006.

19. Kato J, Tsuruda T, Kita T, Kitamura K and Eto T: Adrenomedullin: A protective factor for blood vessels. Arterioscler Thromb Vasc Biol 25: 2480-2487, 2005.

20. Tsuruda T, Kato J, Hatakeyama K, et al: Antifibrotic effect of adrenomedullin on coronary adventitia in angiotensin II-induced hypertensive rats. Cardiovasc Res 65: 921-929, 2005.

21. Irzmański R, Pawlicki L, Charłusz M and Kowalski J: Concentration of natriuretic peptides in patients suffering from idiopathic arterial hypertension and left ventricular diastolic dysfunction confirmed by echocardiography. Clin Exp Hypertens 34: 530-540, 2012.

22. Kohno M, Hanehira T, Kano H, et al: Plasma adrenomedullin concentrations in essential hypertension. Hypertension 27: 102-107, 1996

23. Kong DG, Gao H, Lu YQ, et al: Anxiety disorders are associated with increased plasma adrenomedullin level and left ventricular hypertrophy in patients with hypertension. Clin Exp Hypertens 36: 27-31, 2013.

24. Grzywa-Celińska A, Celiński R, Kwaśniewska K, Dyczko M, Prystupa A and Mosiewicz J: The usefulness of natriuretic peptides measurements in the diagnostics of chosen cardiovascular diseases. Pol Merkur Lekarski 34: 232-234, 2013.

25. Halawa B: Plasma adrenomedullin concentration in patients with essential hypertension. Pol Merkur Lekarski 5: 111-113, 1998. 